\title{
Transient Hyperthyroidism AFTER SURGERY FOr SECONDARY Hyperparathyroidism: A Common Problem
}

\author{
G. Rudofsky¹, M. Tsioga'1, P. Reismann², C. Leowardi³, S. Kopf1', I. A. Grafe'1, \\ P. P. Nawroth 1 , B. Isermann ${ }^{1}$
${ }^{1}$ Department of Endocrinology and Clinical Chemistry, University of Heidelberg, Heidelberg, Germany
${ }^{2}$ Second Department of Medicine, Semmelweis University, Budapest, Hungary
${ }^{3}$ Department of General Surgery, University of Heidelberg, Hcidelberg, Germany

\begin{abstract}
Background: Postoperative hyperthyroidism occurs in approximately one third of patients following parathyroidectomy due to primary hyperparathyroidism (PHP), but has only rarely been described in secondary hyperparathyroidism (SHP). The frequency, course, and laboratory markers of postoperative hyperthyroidism in SHP remain unknown. Our purpose was to evaluate the frequency and the clinical course of postoperative hyperthyroidism following surgery of SHP and to determine the diagnostic value of thyroglobulin in this setting.

Material and Methods: A total of 40 patients undergoing parathyroidectomy because of SHP were included in this study. Thyroid stimulating hormone (TSH), free triiodothyronine (f $\mathrm{T} 3$ ), free thyroxine (f厂4), and thyroglobulin $(\mathrm{Tg})$ were determined one day before and on day $1,3,5,10$, and 40 after surgery. At each of these visits patients were clinically evaluated for signs or symptoms of hyperthyroidism.

Results: Biochemical evidence of hyperthyroidism was evident in $77 \%$ of patients postoperatively despite of preoperatively normal serum levels. TSH dropped from $1.18 \pm 0.06 \mathrm{mU} / \mathrm{L}$ to $0.15 \pm 0.07 \mathrm{mU} / \mathrm{L}(\mathrm{p}=$ $0.0015)$. Free triiodothyronine (fT3) and fT4 levels increased from $2.86 \pm 0.02 \mathrm{ng} / \mathrm{L}$ and $10.32 \pm 0.13 \mathrm{ng} / \mathrm{L}$, respectively, to their maximum of $4.83 \pm 0.17 \mathrm{ng} / \mathrm{L}$ and $19.35 \pm 0.58 \mathrm{ng} / \mathrm{L}$, respectively. Thyroglobulin levels rose from $3.8 \pm 0.8 \mathrm{ng} / \mathrm{mL}$ to $111.8 \pm 45.3 \mathrm{ng} / \mathrm{mL}$ $(\mathrm{p}<0.001)$. At day 40 all thyroid related laboratory values were within normal range. Correlation analysis of postoperative values revealed significant correlations for lowest TSH $(r=-0.32 ; p=0.038)$, and highest fT3 $(\mathrm{r}=0.55 ; \mathrm{p}<0.001)$ and $\mathrm{fT} 4$ levels $(\mathrm{r}=0.67 ; \mathrm{p}<0.001)$ with $\mathrm{Tg}$.

Conclusion: Transient hyperthyroidism is frequent after parathyroidectomy for SHP with $\mathrm{Tg}$ being a suitable marker. Awareness of this self-limiting disorder is important to avoid inappropriate and potentially harmful treatment.
\end{abstract}

Key words: hyperthyroidism, secondary hyperparathyroidism, palpation thyroiditis, parathyroidectomy, thyroglobulin

\section{INTRODUCTION}

Nearly all patients with chronic renal failure on longterm hemodialysis develop secondary hyperparathyroidism due impaired renal function resulting in a deficiency of 1,25-deoxycholecalciferol [1]. In most of these patients secondary hyperparathyroidism can be managed by medical therapy. However, in approximately $5 \%$ of these patients' longstanding secondary hyperparathyroidism progresses into an autonomous function of parathyroid cells, hypercalcemia and an inability of vitamin D analogues to suppress parathyroid hormone despite increasing serum calcium levels [2]. In these patients parathyroidectomy is the only effective treatment. The fact that four-gland hyperplasia is most commonly observed in these patients necessitates intraoperative evaluation of all four parathyroid glands with total or subtotal parathyroidectomy in these patients [2-4].

Postoperative hyperthyroidism is a complication occurring after parathyroidectomy in primary hyperparathyroidism (PHP) [5-11], and is attributed to palpation thyroiditis [12]. Palpation thyroiditis histologically imposes as a multifocal granulomatous folliculitis, which is a common finding following intraoperative manipulation of the thyroid gland. Palpation thyroiditis is supposed to result from traumatic injury or rupture of isolated thyroid follicles caused by pressure on the gland [12]. Two studies evaluated newly diagnosed hyperthyroidism following surgery in patients with primary hyperparathyroidism (PHP) [6, 8]. Abnormal blood values of TSH, fT3, or fT4 indicating postoperative hyperthyroidism were observed in $31.2 \%$ and $42.3 \%$ of patients, respectively, in these studies. Furthermore, $15.0 \%$ and $34.6 \%$ of patients, respectively, reported symptoms of hyperthyroidism one to two weeks after operation $[6,8]$. A marker of thyroid trauma has not been reported hitherto, but thyreoglobulin, presumably being released from the injured thyroid follicles, may be a suitable marker.

Only few case studies report the occurrence of postoperative hyperthyroidism in renal patients undergoing parathyroidectomy because of SHP [9-11]. Up to now the frequency and natural course of postoper- 
ative hyperthyroidism remains unknown in these patients. We hypothesize that the frequency of postoperative hyperthyroidism is even higher compared to patients with PHP due to the intraoperative preparation of all four glands associated with an increased manipulation of the thyroid gland. Hence we prospectively enrolled 40 consecutive haemodialysis patients undergoing parathyroidectomy because of SHP at the University Hospital of Heidelberg. The frequency, duration and severity of postoperative hyperthyroidism as well as the diagnostic value of thyroglobulin ( $\mathrm{Tg})$ as a marker for postoperative hyperthyroidism were evaluated in this study.

\section{METHODS}

This prospective monocentric trial was performed in forty consecutive patients undergoing parathyroidectomy because of SHP at the surgical department of the University Hospital of Heidelberg. The study was approved by the local ethics committee, and all patients gave written informed consent. The study was conducted from April 2008 to January 2009. Patients were eligible for the study if they had SHP. Exclusion criteria were preoperative thyroid medication, known thyroid dysfunction, or prior thyroid or parathyroid surgery. Further, only patients without clinical suspicion or a history of concomitant autoimmune thyroiditis were included. Therefore, in the first ten patients this approach was evaluated with determining TSH receptor [TRA], thyroperoxidase [TPOA], and thyroglobulin [TgA] antibodies [13]. Hyperthyroidism was biochemically defined as serum TSH below $0.40 \mathrm{mU} / \mathrm{L}$.

\section{Operative Management}

All procedures were performed under general anaesthesia and orotracheal intubation. Following a Kocher incision, preparation and mobilisation of the thyroid and parathyroid glands, all four parathyroid glands were identified and removed. Intraoperative serum PTH measurements were performed to assure that all parathyroid glands had been removed. After frozensection confirmation, an autotransplantation into the tibialis muscle was performed. Intravenous gluconate calcium was administered after the last parathyroid removal to prevent severe hypocalcaemia.

\section{Perioperative ManAgEMENT}

Patients were evaluated by an endocrinologist at visits one day before and on day 1, 3, 5, 10, and 40 after surgery. Typically, patients were discharged from the hospital on day 5 and returned on day 10 and 40 after operation to the outpatients' clinic of the Department of Endocrinology. At each visit blood was taken and patients were evaluated by an endocrinologist. Patients were queried with open-ended questions regarding problems, symptoms, and insomnia. Their pulse, weight, and blood pressure were recorded. The physician was unaware of the laboratory test results when recording the patients history and performing the clinical evaluation. At each visit a full thyroid function test panel was obtained (TSH, free triiodothyronine [fT3], free thyroxine [fT4]) and thyroglobulin [Tg]). Patients were maintained post-operatively on calcium and calcitriol to avoid hypocalcaemia.

Seventeen patients suffering from hyperthyroidism due to other causes (Graves' disease: $\mathrm{n}=7$, autonomous thyroid adenoma: $\mathrm{n}=10$ ) were recruited at the outpatients' clinic of the Department of Endocrinology serving as non-operative control group. Blood was taken at fasting state at 8:00 in the morning. Diagnoses were made according to the current guidelines.

\section{STATISTICS}

Results of biochemical measurements are expressed as median \pm standard error of the mean (s.e.m.) and Mann-Whitney $U$ test for unmatched, nonparametric continuous variables was used for statistical comparisons. Results of frequencies and rates are given as mean with the corresponding 95\% confidence interval and the chi-square test $\left(\chi^{2}\right)$ for univariate analysis of categorical data was used. $\mathrm{P}$-values $<0.05$ were considered statistically significant.

\section{RESULTS}

Forty patients with the diagnosis of secondary hyperparathyroidism due to chronic renal failure were referred to the Department of General Surgery at the University Hospital of Heidelberg in Germany for surgical treatment. Demographic information as well as PTH and calcium levels before and after surgery is summarized in Table 1. Both pre- and postoperative laboratory thyroid tests were available in all 40 study patients. One patient was noted to have preoperative subclinical TSH suppression, which persisted postoperatively. This patient was excluded from analysis. Further, to exclude an underlying autoimmune disease as a possible cause for hyperthyroidism antibody testing of TRA, TPOA, and TgA was performed in the first ten patients and in further 5 patients based on clinical suspicion. All antibody tests were negative.

In total, 30 of the 39 patients $[77 \%$; 95\% confidence interval (95\%-CI): $64-90 \%$ ] with preoperatively normal serum TSH, fT3, and fT4 displayed postopera-

Table 1. Patients' characteristics of all 39 patients undergoing parathyroidal surgery are displayed. Mean values and their standard deviation are given.

\begin{tabular}{lc}
\hline $\mathrm{N}$ & 39 \\
Age [yr] & $41.5 \pm 13.2$ \\
Gender [m/f] & $24 / 15$ \\
Dialysis [n] & 39 \\
Duration of Need of Dialysis [yr] & $5.4 \pm 3.7$ \\
Operation time [min.] & $192 \pm 81$ \\
iPTH preoperative [pmol/L] & $140.1 \pm 111.3$ \\
iPTH postoperative [pmol/L] & $2.7 \pm 4.8$ \\
$\mathrm{Ca}^{2+}$ preoperative [mmol/L] & $2.50 \pm 0.23$ \\
$\mathrm{Ca}^{2+}$ postoperative [mmol/L] & $1.92 \pm 0.21$ \\
\hline
\end{tabular}

$\mathrm{Ca}^{2+}$ : calcium; iPTH: intact parathormone. 


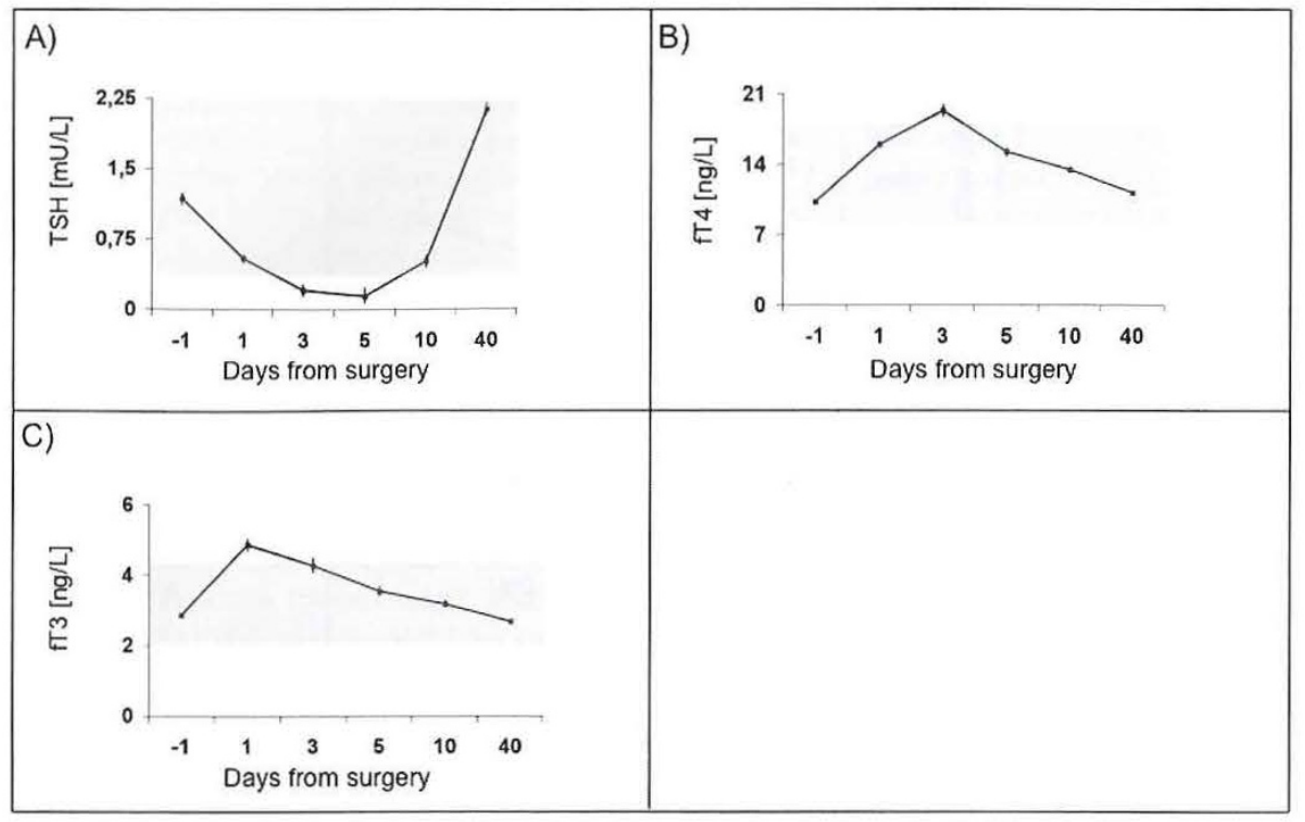

Fig. 1. Time course of biochemical thyroid function markers in all patients undergoing parathyroidal surgery $(\mathrm{n}=39)$. Mean value \pm s.e.m. are shown (A-C). A) Time course of thyroid stimulating hormone (TSH, $\mathrm{mU} / \mathrm{L}$ ); the light grey box marks the normal range of TSH $(0.4$ to $4.0 \mathrm{mU} / \mathrm{L})$. B) Time course of free thyroxine (fT4, ng/L); the light grey box marks the normal range of fT4 ( 8.0 to $18.0 \mathrm{ng} / \mathrm{L})$. C) Time course of free triiodothyronine (fT3, ng/L); the light grey box marks the normal range of fT3 (2.0 to $4.2 \mathrm{ng} / \mathrm{L})$.

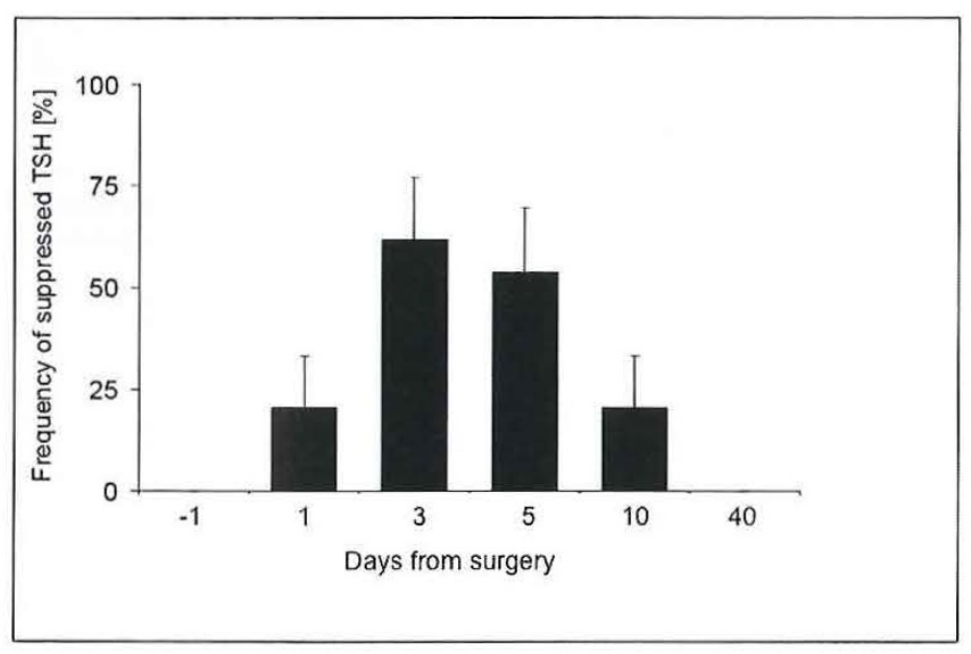

Fig. 2. Frequency of biochemical hyperthyroidism $(\mathrm{TSH}<0.40 \mathrm{mU} / \mathrm{L})$ in all patients $(\mathrm{n}=39)$ undergoing parathyroidal surgery. Frequency is shown separately for one day before surgery $(-1)$, and the first (1), third (3), fifth (5), tenth (10), or fortieth (40) day after surgery. The highest frequency of $61.5 \%$ is observed on the third day after surgery. One day before and at day 40 after surgery no patient with biochemical hyperthyroidism was observed. tively biochemically hyperthyroidism with TSH levels below the lower normal range of $0.40 \mathrm{mU} / \mathrm{L}$. Levels of TSH dropped significantly from a preoperative lev$\mathrm{el}$ of $1.18 \pm 0.06 \mathrm{mU} / \mathrm{L}$ to $0.15 \pm 0.07 \mathrm{mU} / \mathrm{L}$ postopcratively $(p=0.0015$ ) (Fig. 1A). This TSH-drop was paralleled by an increase of the free hormones $\mathrm{fT} 4$ and $\mathrm{fT} 3$ from $10.32 \pm 0.13 \mathrm{ng} / \mathrm{L}$ to $19.35 \pm 0.58 \mathrm{ng} / \mathrm{L}$ $(\mathrm{p}<0.001)$ and from $2.86 \pm 0.02 \mathrm{ng} / \mathrm{L}$ to $4.83 \pm 0.17$ $n g / L(p<0.001)$, respectively (Fig. 1 B, C). At the end of the observation period at day forty after surgery all thyroid related laboratory values had returned to their normal values in all studied subject (TSH $2.14 \pm 0.07$ $\mathrm{mU} / \mathrm{L}$, fT4 $11.20 \pm 0.19 \mathrm{ng} / \mathrm{L}$, and fT3 $2.68 \pm 0.03$ ng/L, Fig. 1 A-C). Free Triiodothyronine and fT4 reached their maximum after surgery on day 1 and day 3, respectively (Fig. $1 \mathrm{~B}, \mathrm{C}$ ). The TSH nadir was reached at the fifth day after surgery, at which time 21 patients (54\%; 95\%-CI: $46-62 \%)$ displayed TSH value lower than $0.40 \mathrm{mU} / \mathrm{L}$ (Fig. 2).

Eighteen of the 30 patients with biochemical hyperthyroidism (60\%; 95\%-CI: 423 - 78\%) complained about hyperthyroid symptoms, representing $46 \%$ (95\%-CI: $31-62 \%$ ) of all 39 patients undergoing parathyroidal surgery.

Thyroglobulin was evaluated as a marker of thyroid trauma. Preoperatively, Tg values were within the normal range, averaging $3.8 \pm 0.8 \mathrm{ng} / \mathrm{mL}$ (normal: $<30$ $\mathrm{ng} / \mathrm{mL}$ ). Postoperatively, $\mathrm{Tg}$ increased up to $111.8 \pm$ $45.3 \mathrm{ng} / \mathrm{mL}$ (Fig. $3 \mathrm{~A}$ ) and displayed maximum values on the first postoperative day $(\mathrm{p}<0.001)$ and returned to normal values $(3.5 \pm 1.2 \mathrm{ng} / \mathrm{mL})$ at day 40 after surgery. Further, correlation analysis revealed a robust and significant correlation of the highest $\mathrm{Tg}$ with all three functional thyroid values. The correlation of 


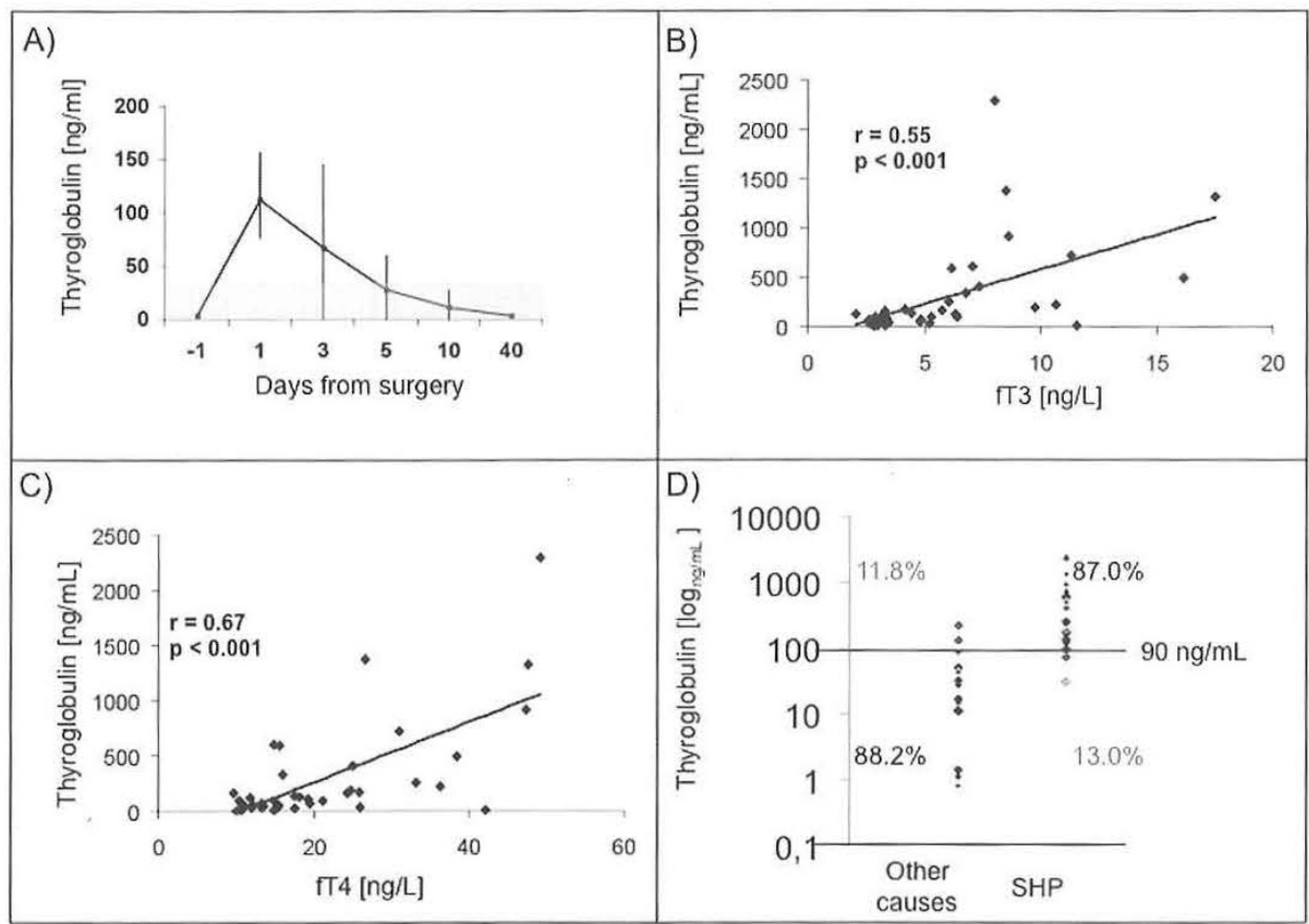

Fig. 3. A) Time course of $\mathrm{Tg}$ in $[\mathrm{ng} / \mathrm{mL}]$ in all patients undergoing parathyroidal surgery $(\mathrm{n}=39)$; the light grey box marks the normal range of ' $\mathrm{Tg}$ (up to $30 \mathrm{ng} / \mathrm{L}$ ); Mean value \pm s.e.m. are shown. B) Correlation of $\mathrm{Tg}$ with free triiodothyronine is given (r $=0.55 ; \mathrm{p}<0.001)$. C) Correlation of $\mathrm{Tg}$ with free thyroxine is given $(\mathrm{r}=0.67 ; \mathrm{p}<0.001)$. D) Distribution of $\mathrm{Tg}$ values of hyperthyroid patients after SHP surgery and patients with hyperthyroidism due to other causes of hyperthyroidism are displayed. Using a cut-off of $90 \mathrm{ng} / \mathrm{mL}$ gives a good diagnostic sensitivity and specificity. Values outlying the cut-off and their corresponding rates are highlighted in grey.

Table 2. Thyroid function of hyperthyroid patients after parathyroidal surgery $(\mathrm{n}=30)$ is compared with hyperthyroid patients due to other causes ( $n=17$; Graves' disease: $n=7$, autonomous thyroid adenoma: $n=10)$ serving as control group. Medians \pm standard errors are displayed. A two tailed student's-t test was used.

\begin{tabular}{lccc}
\hline & $\begin{array}{c}\text { Hyperthyroid patients } \\
\text { after SHP surgery } \\
\mathrm{n}=30\end{array}$ & $\begin{array}{c}\text { Control group } \\
\mathrm{n}=17\end{array}$ \\
\hline TSH [mU/L] & $0.13 \pm 0.02$ & $0.01 \pm 0.01$ & 0.003 \\
$\mathrm{fT} 3[\mathrm{ng} / \mathrm{L}]$ & $6.47 \pm 0.68$ & $5.40 \pm 1.61$ & 0.30 \\
$\mathrm{fT} 4[\mathrm{ng} / \mathrm{L}]$ & $22.33 \pm 2.14$ & $16.33 \pm 4.55$ & 0.87 \\
Thyroglobulin $[\mathrm{ng} / \mathrm{mL}]$ & $373.6 \pm 93.3$ & $31.6 \pm 12.2$ & 0.01 \\
\hline
\end{tabular}

fT3: free triiodothyronine, fT4: free thyroxine, SHP: secondary hyperparathyroidism, TSH: thyroid stimulating hormone.

TSH with $\mathrm{Tg}$ was weakened by the lower detection limit of TSH of $0.01 \mathrm{mU} / \mathrm{L}$. Nevertheless, the correlation between TSH and $\mathrm{Tg}$ was significant $(\mathrm{r}=-0.32$; $\mathrm{p}=$ $0.038)$. Correlation with $\mathrm{fT} 3(\mathrm{r}=0.55 ; \mathrm{p}<0.001)$ (Fig. $3 \mathrm{~B}$ ), and fT4 levels $(\mathrm{r}=0.67$; $\mathrm{p}<0.001)$ (Fig. $3 \mathrm{C}$ ) was more pronounced. Furthermore, the amount of $\mathrm{Tg}$ elevation after operation correlated significantly with the duration of the surgical procedure ( $\mathrm{r} 0.55 ; \mathrm{p}=0.002)$.

Furthermore, $\mathrm{Tg}$ levels of hyperthyroid post surgery patients $(\mathrm{n}=30)$ were compared with $17 \mathrm{pa}$ tients suffering from hyperthyroidism due to other causes (Graves' disease: $\mathrm{n}=7$, autonomous thyroid adenoma: $n=10$ ) serving as control group (Table 2, Fig. 3D). Although values of free hormones fT3 and fT4 were not significantly different between both groups, postoperative hyperthyroidism was associated with significantly higher levels of $\mathrm{Tg}$ in patients displaying postoperative hyperthyroidism (patients with postoperative hyperthyroidism $(\mathrm{n}=30): 373.6 \pm 93.3$ $\mathrm{ng} / \mathrm{mL}$ vs. patients with hyperthyroidism of other causes $(\mathrm{n}=17): 31.6 \pm 12.2 \mathrm{ng} / \mathrm{mL}, \mathrm{p}=0.01) . \mathrm{A} \mathrm{Tg}$ cut-off value of $90 \mathrm{ng} / \mathrm{mL}$ gave a good discrimination of both groups with a sensitivity of $87.0 \%$ and a specificity of $88.2 \%$ in this setting (Fig. 3D).

\section{DiscusSION}

This study shows that biochemical signs of hyperthyroidism are frequently observed in the immediate days after successful and otherwise uncomplicated parathy- 
roidectomy due to SHP. Further, the results indicate that $\mathrm{Tg}$ is a suitable marker supporting the diagnoses of postoperative hyperthyroidism.

Up to now, only a few case reports described transient hyperthyroidism following surgery for SHP [7, 9, $10,11]$. This is the first prospective study evaluating the frequency and natural course of postoperative hyperthyroidism in patients with SHP. Compared to studies evaluating patients undergoing parathyroidal surgery due to primary PHP $[6,8]$ we observed a much higher frequency of postoperative hyperthyroidism. The rate of postoperative hyperthyroidism following parathyroidal surgery for PHP ranges between $31 \%$ and $42 \%[6,8]$, while in our cohort 30 of 39 patients $(77 \%)$ developed postoperative hyperthyroidism. Being a monocentric study we can not fully exclude that this effect might be caused due to different operation procedures differing between the study centres. However, it is more likely that the higher incidence rate reflects the different surgical approach of PHP and SHP. In contrast to PHP, where only one preoperatively localized parathyroid gland has to be removed, in patients with SHP all four glands have to be removed [2], resulting in more extensive manipulation of the thyroid gland intraoperatively. Because of the non-daily performed laboratory controls of thyroid function it can not be fully excluded that some subclinical and only moderate cases of hyperthyroidism might have been missed in the current study. Therefore, the rate of hyperthyroidism might even be higher than $80 \%$ in patients operated for SHP.

One may hypothesize that the observed postoperative hyperthyroidism is unrelated to intraoperative thyroid manipulation itself and rather caused c.g. by general anaesthesia agents or perioperative stress. However, this possibility was already ruled out by Lindblom and colleagues who evaluated patients undergoing surgical procedures other than parathyroidectomy [6]. In patients after breast cancer operation they observed a decrease of TSH paralleled by a concomitant decrease of the peripheral hormones fT3 and fT4 [6]. This phenomenon is known as "non thyroidal illness syndrome" and has been attributed to an acute phase response mainly seen in severely diseased patients [13]. Consistent with the data by Lindblom et al. we failed to observe postoperative hyperthyroidism with an increase of $\mathrm{f} \mathrm{T} 3$ and/or $\mathrm{fT} 4$ in patients undergoing operative procedures outside the neck (data not shown).

An unresolved issue is why $23 \%$ of the patients did no develop postoperative hyperthyroidism within the current study. One potential explanation is differences in the anatomical situs, e.g. different size or shape of the thyroid gland. Indeed, variations of the thyroid size or shape have been demonstrated to affect thyroid pathologies associated with parathyroidectomy [14]. Unfortunately, a preoperative ultrasound of the thyroid gland was not obtained in our study, and hence this issue needs to be addressed in future studies.

The time course and spontaneous resolution of hyperthyroidism in this study are consistent with surgical trauma being the primary cause of postoperative thyrotoxicosis $[4,5,8,11]$. Following surgical trauma one would expect an increase within the first days postoperatively and, based on the half-life (fT4: 8 days), bio- chemical persistence for up to four weeks [15]. Spontaneous resolution after forty days, as observed in the current study in all patients, can be expected in these patients. If hyperthyroidism persists beyond forty days after surgery it is mandatory to search for other causes of hyperthyroidism, e.g. Graves' discase or autonomous thyroid adenoma, because these conditions require a different therapeutic approach, including thyroid suppressive drugs.

Interestingly, despite biochemical evidence for hyperthyroidism in more than three quarters of all patients, hyperthyroid symptoms were less frequent and rather mild. Eighteen patients $(46.2 \%)$ complained about hyperthyroid symptoms, mainly diarrhoea and tremulousness. Since post-operative hyperthyroidism is not caused by an enhanced production but by an increased TSH receptor independent release of thyroid hormones secondary to surgical trauma, thyroid suppressive drugs are not indicated, although this has been proposed by others [6]. However, $\beta$-blockers may be appropriate for marked symptomatic thyrotoxicosis and are strongly recommended and indicated especially if the patient suffers from coronary heart disease $[16,17]$. Consistently, thyroid suppressive medication (e.g. carbimazole) was not started in any patients in the current study and all thyroid blood values returned to normal values. However, symptomatic treatment with propranolol was required in one patient because of symptomatic tachycardia.

Furthermore, our results suggest that $\mathrm{Tg}$ is a suitable marker in diagnosing palpation thyroiditis. Thyroglobulin is a large molecule with a molecular weight of $330 \mathrm{kD}$. It is solely expressed in the thyroid gland. Iodinated $\mathrm{Tg}$ is stored in the lumen of the thyroid follicles and serves as thyroid hormone storage protein. Thyroglobulin levels in the plasma are low in healthy individuals and only elevated following injury of follicles, e.g. in thyroid cancer or Grave's disease [18, 19].

Thyroglobulin elevation correlates very well with postoperative hyperthyroidism in the current study. Further, the comparison of $\mathrm{Tg}$ values of hyperthyroid SHP patients with ' $\mathrm{Tg}$ values in patients with hyperthyroidism due to other causes showed a good sensitivity and specificity using a cut-off value of $90 \mathrm{ng} / \mathrm{mL}$. Therefore, elcvated Tg after parathyroid surgery, especially when higher than $90 \mathrm{ng} / \mathrm{mL}$, supports the diagnosis of a postoperative transitory palpation thyroiditis. Future studies are required to confirm the cut-off level defined in this study.

In conclusion, parathyroidectomy in patients with SHP causes frequently postoperative hyperthyroidism with transient hyperthyroidism, most likely reflecting palpation thyroiditis. Further, $\mathrm{Tg}$ is marker aiding the diagnoses of palpation thyroiditis. Awareness of this self-limiting disorder is important to avoid inappropriate and potentially harmful treatment to the patients. When necessary, $\beta$-blockers may be required to control symptoms of hyperthyroidism, but treatment with thyrostatic drugs is not indicated.

\section{Clinical Trials. gov Identifier: NCT01095341}

Disclosure: There is no conflict of interest in regard of this study.

Grants: The author did not receive funding for this work. 


\section{REFERENCES}

1. Lindberg JS, Culleton B, Wong G, Borah MF, Clark RV, Shapiro WB, Roger SD, Husserl FE, Klassen PS, Guo MD, Albizem MB, Coburn JW (2005) Cinacalcet HCl, an oral calcimimetic agent for the treatment of secondary hyperparathyroidism in hemodialysis and peritoneal dialysis: a randomized, double-blind, multicenter study. J Am Soc Nephrol 16: 800-7

2. Fraser WD (2009) Hyperparathyroidism. Lancet 374: 145158

3. Kebebew E, Duh QY, Clark OH (2004) Tertiary hyperparathyroidism: histologic patterns of disease and results of parathyroidectomy. Arch Surg 139: 974-7

4. Triponez F, Kebebew E, Dosseh D, Duh QY, Hazzan M, Noel C, Chertow GM, Wambergue F, Fleury D, Lemaitre V, Proye CA, Clark OH (2006) Less-than-subtotal parathyroidectomy increases the risk of persistent/recurrent hyperparathyroidism after parathyroidectomy in tertiary hyperparathyroidism after renal transplantation. Surgery 140: $990-7$

5. Walfish PG, Caplan D, Rosen IB (1992) Postparathyroidectomy transient thyrotoxicosis. J Clin Endocrinol Metab 75: 224-7

6. Lindblom P, Valdemarsson S, Westerdahl J, Tennvall J, Bergenfelz A (1999) Hyperthyroidism after surgery for primary hyperparathyroidism. Langenbecks Arch Surg 384: $568-75$

7. Musi N, Braverman LE, Norris CM Jr (2000) Severe thyrotoxicosis after parathyroid surgery for hyperparathyroidism. Am J Med 108: 519-20

8. Stang MT, Yim JH, Challinor SM, Bahl S, Carty SE (2005) Hyperthyroidism after parathyroid exploration. Surgery 138: 1058-64

9. Lederer SR, Schiffl H (2008) Transient hyperthyroidism after total parathyroidectomy for tertiary hyperparathy roidism: a report of two cases. Wien Klin Wochenschr 120: $432-4$

10. Sato H, Miyamoto $Y$, Inagaki M, Kanai G, Suzuki $H$, Tanaka R, Kakuta T, Saito A (2008) Atrial fibrillation induced by post-parathyroidectomy transient thyrotoxicosis. Intern Med 47: 1807-11
11. Rudofsky G Jr, Grafe IA, Metzner C, Leowardi C, Fohr B (2009) Transient post-operative thyrotoxicosis after parathyroidectomy. Med Sci Monit 15: CS41-3

12. Hwang TS, Park SH (1988) Histopathologic study of the so called 'palpation thyroiditis'. J Korean Med Sci 3: 27-9

13. Warner MH, Beckett GJ (2010) Mechanisms behind the non-thyroidal illness syndrome: an update. J Endocrinol 205:1-13

14. Heizmann O, Viehl C'T, Schmid R, Müller-Brand J, Müller B, Oertli D (2009) Impact of concomitant thyroid pathology on preoperative workup for primary hyperparathyroidism. Eur J Med Res. 28: 37-41

15. McGowan DM, Vaswani A, Shperling I (1991) Coexisting hyperparathyroidism with thyrotoxicosis. J Endocrinol Invest 14:305-10

16. Jansson S, Lie-Karlsen K, Stenqvist O, Körner U, Lundholm K, Tisell LE (2001) Oxygen consumption in patients with hyperthyroidism before and after treatment with beta-blockade versus thyrostatic treatment: a prospective randomized study. Annals of Surgery 233: 60-4

17. Nayak B, Burman K (2006) Thyrotoxicosis and thyroid storm. Endocrinology and Metabolism Clinics of North America 35:663-86

18. Lin JD. Thyroglobulin and human thyroid cancer (2008) Clin Chim Acta 2008; 388:15-21

19. Brown RS (2009) Autoimmune thyroid disease: unlocking a complex puzzle. Curr Opin Pediatr 2009; 21: 523-8

Received: March 29, 2011 / Accepted: April 11, 2011

Address foe correspondence:

Gottfried Rudofsky, MD

Division of Endocrinology and Clinical Chemistry

Department of Mcdicine

Im Neuenheimer Feld 410

69120 Heidelberg

Germany

Tel.: $\quad+49-6221-5638620$

Fax: +49-6221-564233

E-mail: gottfried_rudofsky@med.uni-heidelberg.de 